Article

\title{
Sustainable Agriculture and Quality of Working Life: Analytical Perspectives and Confirmation from Research
}

\author{
Giorgio Gosetti \\ Department Human Science, University of Verona, Lungadige Porta Vittoria 41, 37129 Verona, Italy; \\ giorgio.gosetti@univr.it; Tel.: +39-045-820-8650
}

Received: 25 August 2017; Accepted: 26 September 2017; Published: 28 September 2017

\begin{abstract}
We begin by examining the multidimensional nature of sustainability, a concept we generally understand in terms of three overarching dimensions (environmental, social and economic), and propose that the concept of social sustainability be translated in terms of those aspects that we believe connote good working conditions. Stepping beyond a concept of sustainability that is dependent on the imposition of limits, we take as our starting point the concept of decent work adopted by the International Labour Organization (ILO) and argue that it is possible to conceive of, and even design, a sustainable job within a sustainable economy and society by thinking in terms of quality of working life. Subsequently, having introduced some of the changes we are witnessing in the world of work, and in the agricultural sector in particular, we provide a theoretical and methodological description of a model framework we propose for analysing quality of working life. In the concluding part of the essay, we include some of the results of a research project that investigated quality of working life among employees of farms and agricultural businesses in a province in northern Italy.
\end{abstract}

Keywords: sustainability; agriculture; quality of work; quality of working life; work culture; meanings of work

\section{Introduction: Sustainability as a Multidimensional Concept}

Sustainable societies ascribe importance to continuity. They are careful not to compromise the physical, economic and social systems on which they are founded. They also look forward towards future generations, to their capacity to satisfy their own requirements and the options available for doing so [1]. As such, sustainability can be seen to have a diachronic quality linked to the possibility of forwarding resources to future generations [2]. Thus far, in our own societies, we have tied the concept of well-being to that of growth [1], and we have struggled even to acknowledge that this growth may have a limit. The preferred model of development in modern societies, which is overwhelmingly based on the notion of unlimited expansion, has led to a deterioration in our relationship with the human and environmental reality that surrounds us [2]. The "survival" of our society, however, requires greater harmony between its constituent organizations and their environment, and therefore greater attention to the norms that might reign in this excess and sense of limitlessness, albeit such norms-and the limits-are arbitrary and the boundaries uncertain [3]. The redefinition of (geographical, political, cultural, physical, ecological, and economic) limits (and others) thus becomes a social process based on collective discussion and debate, primarily in relation to the excess that characterizes modes of production and consumption [3]. This collective search for a "sense of limit" can be generated through public debate, and the creation of opportunities for developing new, justice-oriented norms.

Sustainability also refers to a system's ability to avoid eroding its social resources, and to avoid colonizing and instrumentalizing social bonds for economic ends. It implies a degree of self-reflection, and an ability among individuals within a collective (be it defined by geography, a common profession, 
shared beliefs, or whatever) to value intangible benefits-experience, identity, meaning and so forth-rather than material goods [4]. Sustainability, therefore, is also concerned with what things mean to us (work, life, etc.) and re-formulating the meaning of the social bond. Ours, then, is a search for the "meaning" of work, one that must consider work's various qualities, and the increasingly blurred boundaries between the worlds of work, production and consumption [5].

Sustainability, particularly insofar as it relates to agriculture, can be considered in terms of certain key concepts [6]. Sustainable agriculture implies an integrated system with a long-term outlook, one that is concerned with the different factors that contribute to quality of life, the improvement of the environment, the efficient use of non-renewable resources, and the increased use of renewable alternatives. It can be analysed, for instance, by observing a number of different levels of a system in socio-ecological terms: the system's efficiency in reducing inputs; how inputs are used and the extent to which they can be replaced; redesigning the system along ecological principles; the redefinition of the relationship between producer and consumer [7]; equity and the possibility of participating in the food production system. Sustainability, therefore, has an ethical dimension associated with numerous elements of the production, distribution and consumption of food products [8], an agricultural ethics that raises issues around the values and norms of the food industry and agriculture system.

The multidimensional nature of the concept of sustainability in agriculture is clear for all to see. It is implied in the Sustainability Assessment of Food and Agriculture Systems (SAFA) guidelines published by the Food and Agriculture Organization of the United Nations [9], which list four dimensions of sustainability: good governance, environmental integrity, economic resilience and social well-being. Velten, Leventon, Jager and Newig [6], meanwhile, have carried out a thorough analysis of the literature in which they highlight the variability among definitions of sustainable agriculture and identify multiple categories and themes, which they group into Goals, Strategies and Fields of Action. Under Goals of sustainable agriculture, in particular, they group a number of broad themes (which we might consider different dimensions of sustainable agriculture): (1) Overarching Goals (which include the subcategories of: ethics; multifunctionality; safety; and stability and resilience); (2) Environmental Goals: (2a) Production-Specific (which include: ecosystem function conservation; natural resource conservation; and productive capacity); and (2b) Non-Production-Specific (which include: animal well-being; environment conservation and improvement; and harmony with nature); (3) Social Goals (which include: acceptability; cultural preservation; equity, justice, fairness; fulfilment of human needs; good working conditions; human health; nourishment; life quality; and strong communities); and (4) Economic Goals (which include: development; livelihood; provision of products; and thriving economy). More generally, we can say that there are three principal dimensions of sustainability: the environmental, the social and the economic. With this paper, we seek to contribute to the process of translating the concept of sustainability in terms of the social dimension, by presenting an analytical framework based on the concept of good working conditions.

We are not necessarily concerned, in this essay, with a concept of sustainability that relies on limiting growth. Rather, we are interested in sustainability's positive, generative potential, and with the idea of work as a component of sustainability. Taking as our starting point the concept of decent work adopted by the International Labour Organization (ILO) [10,11], we address sustainability specifically in terms of quality of working life. The thesis that we seek to develop over the following pages is that to achieve sustainable jobs in a sustainable society and economy, they have to be designed in terms of quality of working life. Having identified a number of changes currently taking effect in the world of work, and in agriculture in particular, we will map out, in theoretical and methodological terms, our approach to analysing quality of working life. We will then conclude the paper by illustrating a number of outcomes from recent research, which studied the quality of working life of employees of farms and agricultural businesses in a province in northern Italy.

We should specify, at this early stage, that this paper is principally concerned with proposing a theoretical—and sociological—approach to translating the concept of sustainability in relation to working conditions in the agricultural sector, and that it does so by framing its analysis in terms of 
quality of working life. In the final section, we will also present a selection of data from research carried out in an agricultural context. Admittedly, the study in question was not designed to investigate the question of sustainability directly, but it does afford the opportunity both to better illustrate the analytical model we are proposing and, simultaneously, to identify a number of issues that affect agricultural workers and that will need to be addressed if we are to make agricultural work more "sustainable" from the perspective of the worker.

As highlighted above [6], one of the constituent aspects of the concept of sustainability is the "social dimension". Within this, we can identify more specific concerns, such as "good working conditions", or "quality of life". By presenting the analytical model outlined in this paper, we suggest that the concept of "social sustainability" be interpreted by adopting the viewpoint of the worker and, as such, from the perspective of "sustainable work". For a job to be considered sustainable, we maintain that it must offer good quality of working life. This is especially so given the changes we continue to witness not just in agriculture but across the world of work, where changes both in how work is organized and in what it actually comprises threaten to unbalance the working life of the individuals involved. Naturally, framing our analysis in relation to quality of working life does not allow for a comprehensive exploration of the social dimension of sustainability (which could also be examined in terms of changes that affect the cohesiveness of society at a local level, or that have a bearing on social capital, social inequality, social mobility and so on). We might say, however, that using the multidimensional framework described in this paper to examine quality of working life offers insights into questions of economic sustainability (for instance, by considering processes leading to economic impoverishment in work, or the entrenchment of the phenomenon of large numbers of working poor, etc.). Ultimately, what we wish to propose-as we will explain over the following pages-is a model that is expressly designed to form a picture of the sustainability of work (along with any inherent social implications) by studying the relationship between workers and the way their work is organized.

\section{The Changing World of Work}

Agriculture and the world of work are undergoing numerous changes that have also led to renewed interest in the relationship between sustainability and quality of working life. Of these processes, which have brought fresh attention to the field of sociology of work, we would like to highlight the reorganization of chains of production, and specifically the adoption of shifting, network-like models that stretch over larger geographical areas [12-18]. The modularization and greater physical distribution of the processes involved in the production of goods and services-which indicates a more flexible approach to resources (including human resources) - generate a level of discontinuity and instability in workers' career paths and an increase in precarious working conditions [19-24]. A number of authors have described, in some depth, the characteristic qualities of today's global knowledge capitalism [4] and the dematerialization of work it entails. Knowledge, the principal resource of the digital economy, also serves to disseminate the particular, and entirely personal, meanings that individuals attribute to the process of production, a process that constantly taps the resources inherent to human beings (information, preferences, motivation, emotions, etc.) and extracts value from them. The spatial and temporal compression of systems of production are redefining the spatial and temporal dimensions of work. The places used for work are becoming more varied, and are populated with an increasingly varied group of people (in terms of contract, socio-cultural background, values, etc.). The increasing separation of highly-qualified and low-qualification jobs (in a sort of "hourglass" model) is leading to a polarization of working conditions and discrete job markets. More generally, changes in the world of work are weakening the barriers between work and other areas of life. Workers have to be more open to change, and to be multi-functional, pro-active and prepared to invest part of their "own" life (time, space, skills, etc.) in the production process. 
Looking specifically at agriculture, we find a sector characterized by diversification. After all, agriculture is not a single, homogeneous sphere. We find diversity in the types of product produced and the methods used to produce it, as well as working conditions. Generally, when we examine changes in systems for producing goods and services-which are becoming increasingly complex-we find we are witnessing a shift from "integrated" systems of production based on the "unit" of the nuclear family, to more complex, parallel and differentiated systems, which are integrated up- and downstream with industrial processes. Certain trends indicate an agro-industrial sector that is growing in scale $[25,26]$. Another characteristic is the trend towards greater multi-functionality. Farms and agricultural businesses are diversifying: for instance, combining agricultural production with processing, direct sales, energy production, agritourism and the provision of other services. They may also focus more on the social, economic and cultural impact of production, and assume greater responsibility for the preservation of biodiversity and our natural heritage as a whole.

The development of intensive forms of agriculture has led to large-scale production practices and greater concentration of power, processes that threaten smaller producers who are often compelled to operate as part of a wider, large-scale system that determines what they can produce and how they produce it. It is a process that is directed by large, multi-national actors, and one that has led to an increasingly precarious way of life for farmers and weakened their control over the outcomes of their work and the means they have to achieve them [27]. The exploitation of labour in the field of agriculture is most evident in areas (both in the geographical sense, and in terms of industry segment) that make greatest use of migrant workers, who we frequently find in a position of objective weakness [28].

Technological innovation has also made its impression on agriculture; certain activities are becoming increasingly reliant on computers, with a consequent shift in the skill-set required. With this last issue, our discussion has intersected with a dichotomy that lies at the very heart of how we approach the agricultural process: farming as a way of life, or farming as a business venture? The latter approach, which is often considered an artificial construct, is heavily dependent on the market and favours specialization. It contrasts with the farmer-centric vision of agriculture, which is built around concepts of land, work and time as factors that form the foundation of production, factors that multifunctional agriculture might once again bring centre stage, inasmuch as it requires a "central moment of creation" that is capable of "generating something unique" [29].

The issue of agriculture-particularly its systems of production and cultivation, and the nature of the work involved - has become a political battleground, with high-profile debates on-going over access to food and food sovereignty [30,31]. Such questions demand ever more complex frameworks of analysis to address the multiplicity of variables involved. Just as interesting are issues such as the means of production, and the methods and technologies used in agriculture. More generally, there are also important questions about how production resources (e.g., seeds) are controlled, and by whom, and the issue of self-determination among producers. Urban food systems, and their impact on ecosystems and socio-economic conditions, form another issue that has already drawn a great deal of attention [32]. All these issues, unfortunately, must fall beyond the scope of this essay, yet they are a constant presence in the backdrop to our considerations [33,34].

The world of agriculture is changing, not least because the relationship between city and countryside is evolving, blurring the boundaries between agriculture and other sectors and redefining the links between farming and the processes of financialization that characterise today's economies [35]. These processes have broken down existing barriers between contexts of work and life only to throw new ones up elsewhere, and they demand an interdisciplinary approach if we are to examine sustainability in all its different aspects [36]. Agriculture, therefore, is a heterogeneous, dynamic field of activity. Within it, we find an increasingly widespread tendency to explore, and propose, alternative visions of production and consumption, and a new enthusiasm, especially, for organic produce, reclaiming of traditional working methods, and forging a lasting connection with the local area [37]. Furthermore, just as we see in the wider world of work, the social composition of the population engaged in agricultural work has changed. It has become more varied. The sector is marked, 
throughout, by processes of migration, yet, at the same time, by an increase in the average age of the working population. There are signs, however, of a renewed interest among young people. The primary draw seems to be the very multi-functionality described above, which brings opportunities to develop a "composite" working set-up. With all these processes at work, the importance of examining the sustainability of working life in this area of our economy should be evident.

\section{Sustainability and Quality of Working Life}

As we suggested in the introduction, we believe it is possible to interpret the idea of sustainability as it pertains to work by using the concept of quality of working life to guide our analysis. We adopted such a framework in a series of studies in the field (three of the most recent being [38-40]). By assuming the worker's perspective, this approach seems to us to be particularly suited to identifying factors that make work—or a job—sustainable.

There is relatively widespread agreement that "quality of work" represents "a multifaceted paradigm, built upon a number of interrelated factors that seek meticulous consideration to conceptualize and measure" [41,42]. The International Labour Organization (ILO) uses the term "decent work", which it defines in terms of "opportunities for women and men to obtain decent and productive work, in conditions of freedom, equity, security and human dignity" [10,11]. The framework proposed by the European Foundation for the Improvement of Living and Working Conditions (Eurofound) is based on four areas of analysis: (1) career and employment security; (2) health and well-being of workers; (3) reconciling working and non-working life; and (4) developing skills and competences $[43,44]$. Writing from a sociological perspective, Gallie suggests that we analyse job quality in terms of five dimensions: (1) skill levels; (2) training opportunities; (3) task discretion; (4) work-family balance; and (5) job security [45,46]. Other authors have identified the various aspects of job quality by differentiating between those that are intrinsic to the job (purpose and tasks involved, opportunities to employ skills and knowledge, etc.) and those that are extrinsic to it (promotion, pay, security, etc.) [47]. Others still draw a distinction between two contrasting perspectives, the subjective, which examines those elements of job quality that are perceived by the individual, and the objective, which is concerned, indeed, with aspects that can be determined objectively, and with the specific characteristics of the workplace $[48,49]$.

Many of the numerous studies dedicated to the question of job quality share a common trait: "multidimensionality". In other words, they opt to interpret working conditions using sets of related indicators and analyse them in terms of multiple aspects. The work of Muñoz de Bustillo, Fernández-Marcías, Esteve and Antón [50] is particularly helpful in understanding the multidimensional nature that an analysis of job quality might assume. In the paper cited, they provide an overview of a series of different analyses, reflecting on the advantages and drawbacks of each, and comparing their conceptual characteristics and the methodological choices involved ("several important methodological dilemmas"). To truly understand work-related well-being, it is necessary to go beyond a mere survey of job satisfaction since, albeit it is a useful broad indicator, this would not break down the structural factors that form the basis of working conditions. Analysis of the sort set out in this paper, where the focus is on multiple dimensions, can facilitate our understanding of the factors that lead to job quality. In the paper referenced above, the authors suggest an analysis model based on a "relatively open operational definition" that: considers the various aspects of work and employment that have a direct impact on the well-being of the worker; captures both the interrelations between relevant job attributes and their relative importance; takes its measurements starting at the level of the individual in such a way that it permits a reading of the distribution of job quality for population subgroups; and aggregates variables, indicators and components, the weighting of which is "derived from theoretical models" or determined by policy requirements. Here, as with other studies, we are directed towards a multidimensional understanding of job quality and the need to consider the relationships between different job attributes. 
The model we present here takes, as its starting point, a line of debate that has been developed in Italy from the 1980s onward. Specifically, it is based on the premise that the key to examining the question of quality of work is the relationship between the needs of the worker and the way the work is organized [51,52]. To put this approach into effect, however, we have found it necessary to introduce a number of additional considerations over the years. First, alongside the consideration of needs, we have incorporated references to aspirations [53] and capabilities [54-56], whereby we seek to evaluate the extent to which the work is organized in a way that enables it not only to meet the aspirations of the worker, but also to cultivate further aspirations and facilitate the acquisition of additional capabilities (learning new skills, coordinated opportunities for professional development, etc.). Furthermore, having observed a number of the changes mentioned earlier, we also think it is helpful to expand the analytical framework, which was based on various dimensions of the quality of work, to include other dimensions that are specifically concerned with the quality of the work-life relationship.

As such, we believe that to evaluate the sustainability of current working conditions, we need to reconfigure two analytical frameworks-one pertaining to quality of work and one pertaining to the quality of the work-life relationship-, combining them to create a more comprehensive model for analysing quality of working life. As such, quality of working life becomes the product (measured in both subjective and objective terms) of the relationship between the needs, aspirations and capabilities of the worker, and the way the work is organized (both in the strictest sense of how work activities and production processes are organized, and at more of a societal level, i.e., social protection, industrial relations, job markets, etc.). To interpret this relationship, our analysis has to assume a relational approach, or in other words, we have to engage in "relational thinking" [57], whereby we consider the impact each element has the others in relation to both the person (needs, aspirations and capabilities) and to the way the work is organized (in both the direct sense, and at societal level): a "relational, but also generative" approach, then [58], in which we combine nine dimensions in terms of which we can analyse and/or programme quality of working life. Six of these dimensions relate to quality of work, three to the quality of the work-life relationship (Table 1). For each one, we consider specific aspects of the relationship between needs/aspirations/capabilities and the organizational set-up of the work [59].

One of the foundational references for the analytical perspective presented here is the writing of Pierre Bourdieu, particularly inasmuch as he maintains that to understand job quality it is necessary to examine the relationship between the person (his or her needs/aspirations/expectations: in a sense, his or her habitus, the collection of lasting attitudes revealed by analysing the individual's "work culture", as we will see) and the relevant organizational context (meaning the way work activities are organized, but also the social organizational framework, social protection, etc.-elements that characterize what Bourdieu calls the "field"). The quality of work cannot be fully grasped either by looking subjectively at the individual's response in terms of perceived well-being (for instance, by studying satisfaction), nor by looking objectively at organizational choices (i.e., modelling aspects such as shift patterns, part-time work, division of labour, time and space devoted to work, etc.). As Bourdieu himself makes clear, to do either would both lead us down the path of subjectivism or objectivism, respectively, and blind us to the fact that working conditions (or rather, quality of working life) are actually the product of a generative relationship between the person and the organizational context.

In methodological terms, the approach presented examines the relationship between different factors and between different dimensions of quality of working life, though it does so starting with the understanding that these serve to measure specific characteristics. It is not possible here to describe all aspects of the study and its results (the reader may wish to seek out the more comprehensive published account [40]). However, lest it be forgotten, we will mention that, despite this recourse to individual dimensions (and associated indicators), both our own research [38-40] and that of other authors $[43,44,60]$ also consider the relationships between them. For instance, groups of workers that evince a favourable status in terms of work complexity frequently produce problematic results for indicators relating to the ergonomic dimension, and positive results for those relating to the question of autonomy. Which is to say that, through multivariate analysis, we can see how complex work 
(which requires the performance of a varied set of tasks, reliance on prior experience, ongoing learning, dealing with unexpected events, etc.) is frequently associated with relatively high psychological and physical demands and a comparable level of autonomy (whereby the worker can determine task order and make decisions on work quality, etc.). Aspects pertaining to autonomy are frequently found to correlate with those associated with involvement in decision-making processes, inasmuch as the potential for making operational decisions is boosted by the opportunity to participate in the (formal and informal) situations in which higher-level decisions are made. However, by bringing the indicators from these two dimensions into relation with one another, the multidimensional model helps us to uncover occasions in which organizational choices can be seen to promote the autonomy of workers without including them in decision-making processes, i.e., the employee is effectively treated as a vehicle through which to effect the duties of the role without involving him or her in any meaningful way in the business's decisions.

Table 1. Perspectives and dimensions of quality of working life used for analysis.

\begin{tabular}{|c|c|c|c|c|}
\hline \multirow{2}{*}{$\begin{array}{l}\text { Perspectives and Constituent } \\
\text { Considerations }\end{array}$} & \multicolumn{4}{|c|}{ Dimensions of the Quality of Working Life } \\
\hline & & Quality of Work & & ality of the Work-Life Relationship \\
\hline $\begin{array}{l}\text { Subjective } \\
\text { (a) } \\
\text { satisfaction } \\
\text { (with the work) } \\
\text { (b) } \\
\text { worker's own assessment } \\
\text { (of the work) }\end{array}$ & (3) & $\begin{array}{l}\text { economic dimension } \\
\text { (basic living costs, financial security, } \\
\text { financial recognition, etc.) } \\
\text { ergonomic dimension } \\
\text { (physical, psychological and social } \\
\text { well-being, psychological and } \\
\text { physical demands, etc.) } \\
\text { dimension of complexity } \\
\text { (commitment and development, } \\
\text { accumulation of experience, } \\
\text { relationality, etc.) } \\
\text { dimension of autonomy } \\
\text { (opportunity to exercise discretion } \\
\text { and determine operational } \\
\text { frameworks, etc.) } \\
\text { dimension of control } \\
\text { (participating in decision making, } \\
\text { control over working conditions, etc.) } \\
\text { symbolic dimension } \\
\text { (appreciation, visibility, social utility, } \\
\text { recognition, etc.) }\end{array}$ & (7) & $\begin{array}{l}\text { work-life balance dimension } \\
\text { (compatibility of work and life } \\
\text { choices, self-determination, etc.) } \\
\text { dimension of social protection } \\
\text { (career planning, continuity of } \\
\text { employment, etc.) } \\
\text { dimension of social engagement } \\
\text { (participation in the life of the wider } \\
\text { society, social involvement, etc.) }\end{array}$ \\
\hline
\end{tabular}

In addition to common statistical instruments (correlation and regression analysis), in some cases, factor analysis can help us draw an effective, if summary, picture of latent dimensions that link factors associated with different dimensions of quality of working life. In short, each indicator has a specific role within the analysis, and must therefore be able to adequately measure a particular aspect of quality of working life, or rather a particular attribute of one of the dimensions identified. Although these indicators are essentially independent within the analysis, there can be close relationships between them. They are certainly an effective means of expressing the relationship between the person and the organizational situation. For these reasons, we maintain that it is unfruitful to attempt to seek a single composite indicator of quality of working life. Rather, we should be attempting to grasp the specific nature of the different dimensions of working life and the relationships between the relative indicators. 
For more on these aspects, which are not central to the arguments we are developing here, we refer the reader to the more detailed publications cited throughout this paper [40,59].

The six dimensions that relate specifically to quality of work are:

(1) The economic dimension is concerned with covering basic living costs, financial security, financial recognition of work carried out and so on, and implies categories of analysis that relate to the individual's economic situation (payment, wages, etc.), economic progress (growth in earnings, etc.), and financial recognition (performance-related pay, productivity bonuses, fringe benefits, etc.).

(2) The ergonomic dimension is concerned with well-being and the psychological, physical and social demands placed on the worker, and which includes categories of analysis such as time (work hours, travel time, etc.), space (space available for work, the possibility of personalizing the workspace, etc.), work intensity (work patterns, workload, etc.), the physical work environment (workstations, physical hazards, etc.), hygiene and environmental factors (presence of chemical/biological agents, noise, extremes of temperature, etc.), physical and psychological demands (repetitive movements, mental effort, emotional involvement, etc.), the social context of the workplace (trust, conflict, discrimination, violence, etc.), tools and instruments (technologies, materials, etc.), purpose (extent to which purpose can be identified, attainability of objectives, etc.) and health and safety (workplace accidents, etc.).

(3) The dimension of complexity is concerned with commitment and professional growth, development of creativity, acquisition of experience, and the relational character of the work involved. It includes categories of analysis such as what the job actually consists of (task variety, problems and unexpected situations, correspondence between tasks and skills possessed, etc.), career development (training, self-training, learning opportunities, etc.), relationships (relations with colleagues, superiors, customers/users, etc.) and dynamism (career options, etc.).

(4) The dimension of autonomy is concerned with the level of discretion afforded to workers, and the degree to which they can determine their own work activities and the wider operative and organizational set-up. This aspect uses categories of analysis such as influence over operational decisions (taking breaks, setting working patterns, task order, how to carry out a particular task, etc.), responsibility (deciding personal work objectives and quality requirements), and resource management (availability of tools and necessary know-how to enable operative decision-making, etc.). For Gallie, Felstead and Green [61,62], this dimension of autonomy is essentially one of "task discretion", or rather "the degree of initiative that employees can exercise over the immediate work task".

(5) The dimension of control is concerned with the possibility of participating in decision-making processes, influencing even long-term strategy and determining—directly or indirectly-one's own working conditions. Here, we find categories of analysis such as the conditions required to exercise control (access to information, space and time dedicated to sharing/involvement, etc.), the decision-making process (participation in meetings, and planning and scheduling processes); and strategic decision-making (participation in meetings where strategic objectives are discussed and decided, and in the process of formulating development plans, etc.). As such, it is a dimension that also helps us in understanding the role of workers in processes of change $[63,64]$.

(6) The symbolic dimension is concerned with recognition, appreciation, social visibility, social utility and a sense of belonging. It includes such categories of analysis as utility of the job (for the worker/organization/worker's family/society, etc.), visibility (social prestige, etc.), appreciation (satisfaction with work performance, etc.), values (congruity of the worker's personal values and the objectives of the organization, etc.), narration (work as a means of telling one's story, etc.).

Turning to the question of the quality of the work-life relationship, this is defined by three dimensions:

(7) The dimension of work-life balance is concerned with the compatibility (or otherwise) of work choices and life choices, and the worker's level of self-determination in defining the relationship 
between work and other areas of life. It includes analysis categories such as boundaries (the relationship between the spaces and times used for work and other areas of life, between objectives/responsibilities in work and in life, etc.), impact (aspects of the job that affect other areas of life, and vice versa, etc.), the way work/the job is organized (flexible working times, etc.), the way the family is organized (allocation and distribution of family tasks, etc.), the way relevant services are organized (services within the organization and within the local area, etc.), image and perception (society's perception of male and female roles, etc.).

(8) The dimension of social protection is concerned with career planning, and the continuity and security of the employment situation. It includes categories of analysis such as continuity (stability of the job/employment situation, continuity of income, continuity in skill development, etc.), accessibility of employment (chances of finding and/or changing job, support during transitional phases, etc.), employment protection (cover for illness, option of taking leave for personal reasons, etc.), and social networks (supportive relationships, formal and informal networks, etc.).

(9) The dimension of social engagement is concerned with the worker's involvement, via work, in the social-economical-cultural life of the local area and the community to which he or she belongs, but also in those of more distant contexts. It therefore relates to the worker's contribution to democratic life and initiatives for development, and includes such categories of analysis as involvement (through work, in social initiatives, and projects that target development and the production of common resources, etc.), and participation (through work, in decision-making processes outside of the organization, affiliation with labour movements and institutions, etc.).

To complete our framework for analysing quality of working life (Table 1), we have to include a tenth area of consideration, discriminating factors. Here, we include various elements grouped in four profiles that we can use to differentiate the various aspects of quality of working life: the person (sex, age, qualifications, etc.), the organization (sector, size, etc.), the immediate context (labour regulations, the system of industrial relations, education system, etc.), and the macro-context (production regime, welfare systems, etc.).

The framework for analysing quality of working life also incorporates two perspectives (Table 2), each comprising two component parts: (1) a subjective perspective, which covers (1a) the worker's level of satisfaction with various aspects of the work (pay, hours, etc.) and (1b) the worker's assessment of how the job/work is organized (work intensity, level of autonomy, etc.); and (2) an objective perspective, which covers (2a) actual working and work-related behaviours (hours worked, journey times to and from work, etc.) and ( $2 \mathrm{~b}$ ) the organizational set-up that conditions the work and the work-life relationship (scheduling of shifts, schemes for allocating days off, etc.).

Compared to Tables 1 and 2, Table 3 presents the two perspectives in more detail, breaking each one down into component aspects and listing the relative objects of analysis. In doing so, it underlines how important it is to identify indicators that can effectively make sense of the various subjective and objective considerations on which our assessment of quality of working life is based. Focusing on the subjective aspects, we can see that these are influenced by the "work culture" of each individual worker.

The framework illustrated here includes another theoretical and methodological supposition, that to understand quality of working life from a subjective perspective (i.e., studying the worker's level of satisfaction and his or her own assessment), we need to know what importance the worker attributes to various aspects of his or her working life (pay, professional development, relationships with colleagues, etc.) We therefore need to examine the individual's "work culture". In this case, too, we believe that a multidimensional approach is essential if we are to identify the various meanings and levels of importance attributed to work. The six dimensions of analysis we consider most important (Table 3) are concerned with the evaluation of: (1) the characteristics of the work that are considered most important (wages, hours, activities involved, etc.); (2) the importance of work, in the sense of how the individual ranks work in the hierarchy of areas of life (family, friends, free time, etc.); (3) experiences 
of work to date, in terms of such aspects as the nature of work performed, career to date (entry into work, contract types), working conditions, etc.; (4) broader changes in the world of work, specifically flexibility (working hours, function, wages, etc.), routes into work, potential for professional growth, etc.; (5) the role attributed to work in the context of personal relationships, and as such, its capacity for generating meaningful relationships, trust, etc.; and (6) the role attributed to work in relation to the wider societal context, e.g., its capacity to generate social integration and cohesion, etc. By analysing these six areas, we can form an understanding of the meaning attributed to work, or rather, we can understand whether the group studied, or a section of it, tends towards a purely practical/expressive/relational (etc.) outlook that might influence its subjective assessment of the quality of working life.

Table 2. Perspectives for analysing quality of working life.

\begin{tabular}{|c|c|c|c|}
\hline Perspective & & Component & Specific Objects of Analysis \\
\hline \multirow{2}{*}{ Subjective } & a & Satisfaction & $\begin{array}{l}\text { Expression of the worker's level of satisfaction in relation } \\
\text { to intrinsic (work times, etc.) and extrinsic (continuity of } \\
\text { employment, work-life balance, etc.) aspects of the job }\end{array}$ \\
\hline & $\mathrm{b}$ & Worker's assessment & $\begin{array}{l}\text { Worker's assessment of certain aspects of his or her job } \\
\text { (intensity, degree of autonomy, options for professional } \\
\text { development, relationships with colleagues, etc.) }\end{array}$ \\
\hline \multirow[b]{2}{*}{ Objective } & $\mathrm{a}$ & Behaviours & $\begin{array}{l}\text { Accounts of actual working behaviours (hours worked, } \\
\text { travel time to and from work, training undertaken, etc.) }\end{array}$ \\
\hline & $\mathrm{b}$ & Organizational set-up & $\begin{array}{l}\text { A model of the organizational set-up affecting work and } \\
\text { the work-life relationship (scheduling of shifts, } \\
\text { availability of services, etc.) }\end{array}$ \\
\hline
\end{tabular}

Table 3. Framework for analysing work culture.

\begin{tabular}{|c|c|c|}
\hline Aspect of Work Culture Analysed & Scope of Analysis & Specific Elements of Analysis \\
\hline (1) Characteristics of the job & $\begin{array}{l}\text { Assessment of the } \\
\text { characteristics of the job that } \\
\text { are considered most important }\end{array}$ & $\begin{array}{l}\text { wages, work hours, nature of work activities, } \\
\text { job security, career prospects, proximity of } \\
\text { workplace and home, relationships with } \\
\text { colleagues, etc. }\end{array}$ \\
\hline (2) Importance of work & $\begin{array}{l}\text { Assessment of the importance } \\
\text { of work in terms of a hierarchy } \\
\text { of different areas of life }\end{array}$ & $\begin{array}{l}\text { work, family, friends, free time, cultural } \\
\text { enrichment, social engagement, political } \\
\text { engagement, religion, financial resources, etc. }\end{array}$ \\
\hline (3) Experiences of work & $\begin{array}{l}\text { Assessment of experiences of } \\
\text { work accrued }\end{array}$ & $\begin{array}{l}\text { nature of the activities performed, career path, } \\
\text { working conditions, social/working } \\
\text { relationships, training completed, etc. }\end{array}$ \\
\hline (4) Changes in the world of work & $\begin{array}{l}\text { Assessment of current and } \\
\text { recent changes in the wider } \\
\text { world of work }\end{array}$ & $\begin{array}{l}\text { flexibility (working hours, function, wages, } \\
\text { etc.), routes into work, potential for career } \\
\text { development, job security, etc. }\end{array}$ \\
\hline (5) Work and personal relationships & $\begin{array}{l}\text { Assessment of the role } \\
\text { attributed to work in relation } \\
\text { to personal relationships }\end{array}$ & $\begin{array}{l}\text { work as a factor in developing meaningful } \\
\text { relationships, social connections, moral } \\
\text { support, trust, shared plans, etc. }\end{array}$ \\
\hline (6) Work and societal context & $\begin{array}{l}\text { Assessment of the role } \\
\text { attributed to work in respect to } \\
\text { the wider societal context }\end{array}$ & $\begin{array}{l}\text { work as a factor in social integration, social } \\
\text { change, social cohesion, social identity, } \\
\text { socio-economic development, well-being, etc. }\end{array}$ \\
\hline
\end{tabular}

\section{Results from a Research Project: The Agricultural Workers of the Province of Verona}

The analytical framework we have presented in the preceding pages has been applied in a number of research projects [38-40]. A recent study in particular, which was carried out in an agricultural context [40], offered the opportunity to gather valuable data on the condition of employees. Over the next few pages, we will limit ourselves to highlighting a few of the more significant findings. 
This paper provides a predominantly descriptive account of the study results. For further details and additional phases of analysis, we refer the reader to the published study [40]. Here, we hope merely to illustrate how the multidimensional profile of quality of working life was interpreted in the analysis, and highlight some of the indicators employed. To demonstrate how the two perspectives on quality of working life-objective and subjective-were brought into relation with one another, we have included a certain amount of data relating to "work culture" (Tables 11 and 12). After all, the meanings attributed to work-i.e., the constituent elements of "work culture" - reflect subjective attitudes that will influence the final evaluation.

In any case, the data presented-which relate to the various dimensions on which the analytical framework is based-are informative and can help us identify aspects of agricultural work that give particular cause for concern. Such concerns could form the basis for further investigation, which itself could represent the next stage in the exploration of "social sustainability" in the agricultural sector, and another opportunity for testing the analytical model proposed.

\subsection{Methodology}

The geographical area of study was the Province of Verona, an administrative province in the north-east of Italy in which a relatively large share of the population is engaged in agricultural work $(6.4 \%)$ compared to the average share across the region (Veneto, $3.1 \%)$ and across Italy as a whole $(3.8 \%)$. We will not provide a full account of the methodology here (see the relevant publication [40]), rather, we will report simply that 79 farms and businesses were involved in the study, these being selected at random-using the criteria of size (number of employees) and produce type-from the records of the sector's three principal trade associations (Coldiretti, Confagricoltura, and the Confederazione Italiana Agricoltori or "CIA"), which represent the majority of agricultural enterprises in the area. The sample included a total of 499 employees (Table 4). A number of additional businesses had to be selected, again at random, to compensate for those that declined to participate $(25 \%)$.

Table 4. Enterprises and workers involved: breakdown by sector.

\begin{tabular}{ccccc}
\hline \multirow{2}{*}{ Sector } & \multicolumn{2}{c}{ Enterprises } & \multicolumn{2}{c}{ Workers } \\
\cline { 2 - 5 } & Absolute Number & $\%$ & Absolute Number & $\%$ \\
\hline Viticulture & 22 & 27.8 & 108 & 21.7 \\
Fruit and Vegetable & 32 & 40.5 & 214 & 42.9 \\
Livestock & 12 & 15.2 & 88 & 17.6 \\
Other & 13 & 16.5 & 89 & 17.8 \\
Total & 79 & 100.0 & 499 & 100.0 \\
\hline
\end{tabular}

More than half of the participants interviewed were male $(58.7 \%$ male; $41.3 \%$ female). Similarly, more than half were foreign nationals (46.5\% Italian; $53.5 \%$ non-Italian). Of the various sectors, "fruit and vegetables" was most heavily represented. The figures relative to farm/business size, however, display a more even distribution of workers (Table 5).

Table 5. Participants interviewed, by sector and business size: comparing Italians and non-Italians (\% values).

\begin{tabular}{cccccccc}
\hline Sector & Italians & Non-Italians & Total Cases & $\begin{array}{c}\text { Size (N. of } \\
\text { Employees) }\end{array}$ & Italians & Non-Italians & Total Cases \\
\hline Viticulture & 25.4 & 18.4 & 21.7 & Up to 5 & 15.1 & 18.0 \\
Fruit and Vegetable & 26.3 & 57.2 & 42.9 & From 6 to 10 & 20.7 & 29.2 & 16.6 \\
Livestock & 23.7 & 12.4 & 17.6 & From 11 to 20 & 23.7 & 26.2 & 25.3 \\
Other & 24.6 & 12.0 & 17.8 & Over 20 & 40.5 & 26.6 & 33.1 \\
Total & 100.0 & 100.0 & 100.0 & Total & 100.0 & 100.0 & 100.0 \\
Base & 232 & 267 & 499 & Base & 232 & 267 & 499 \\
\hline
\end{tabular}


The study, which took its lead from a number of working hypotheses, had the stated objective of investigating quality of working life among employees of agricultural enterprises in the Province of Verona. Data was collected starting at the beginning of 2014, using a series of meetings and focus groups to calibrate the research instruments. Between May and December 2014, a questionnaire was administered, on a face-to-face basis, to the employees during work hours. The questionnaire was administered at the premises of the businesses involved by researchers who had received appropriate training. Between March and May 2015, the research team also carried out 29 interviews with agricultural workers to expand upon a number of aspects that emerged during the questionnaire phase.

The questionnaire comprised six topic areas: (1) a profile of the worker (position in the enterprise, duties, etc.); (2) the meaning of the job/work (the aspects of the job/work that the worker considered most important); (3) work conditions (quality of work, overall satisfaction, training, etc.); (4) work, life and the future (quality of the work-life relationship, prospects for the future, etc.); (5) the farm/company (how he worker view the agricultural enterprise, the role of unions, etc.); and (6) personal profile of the worker (sex, age, level of education, family status, etc.). Each questionnaire was accompanied by a data sheet, on which the researcher recorded information about the interview conditions (modes of interaction, interviewee's reactions, etc.). An information sheet was also completed for each farm/company, profiling its operations and organizational set-up (with information regarding: location, sector, number of employees, workforce profile, major changes in organization/technology/output, internal/external organizational profile, etc.).

\subsection{Results}

As far as the results are concerned, we will limit ourselves to discussing just a few aspects that we believe have some bearing on the broader lines of argument we have developed in this text.

For instance, we identified a significant difference between Italian and non-Italian employees in terms of contract conditions and job grade (Table 6). Almost all of the non-Italian workers had a fixed-term contract (compared to $63.3 \%$ of the Italians). In terms of job grade, non-Italians were also more likely to be qualified only as basic agricultural workers ("operai comuni" in the Italian grading system). As such, as a group, the Italian workers enjoy greater contractual stability and better professional qualifications. Generally, the workers interviewed tended not to have worked for their present employers for a long period (Table 7).

Almost half of the sample group attributed their choice of current employer to the "need to earn money", making this the most common factor indicated in the survey, although frequently this factor was accompanied by another. Indeed, it is important to note that the interviewees were able to give up to two answers. As such, the each percentage given in Table 8 reflects the number of workers who gave that response as a fraction of the total number of respondents. In relation to job grade, the "need to earn money" was a more prevalent response among the "basic workers". Among "qualified" and "specialized" workers, the reason that "it was the job I wanted" appears more frequently than the aforementioned economic consideration. As the worker's grade increases, therefore, the more he or she is concerned with what the job actually is. The immigrant workers surveyed were more likely to indicate practical reasons for their choice, and frequently we find them working in agriculture due to financial necessity.

Table 9 provides us with a classification of the aspects of work that the interviewees, taken as a whole, consider most important. The questionnaire lists eleven job characteristics, each of which could be rated, in terms of importance, as "not at all", "not very", "quite", "very" or "extremely". These five possible answers were translated into a numerical scale from 1 to 5 to obtain the mean values listed in the table. If we split the results into three bands, we find that the top positions are occupied by aspects such as "having a stable job", "relationships with colleagues", and "the opportunity to show what I can do". These reveal a view of work where continuity of employment plays a central role, as do relational and expressive concerns. The mid-table band is filled with a rather heterogeneous list of concerns covering "appreciation for work done", "pay" and "the work environment". Less value is placed 
in aspects such as "working autonomously", "work load and work rhythms" and "opportunities for involvement in decision making within the workplace". The classification varies, however, if we compare the answers from the Italian respondents with those from the non-Italians (Table 10), or those from male respondents with those from women.

Table 6. Breakdown of sample group by contract type and job grade. Comparison between Italians and non-Italians (\% values).

\begin{tabular}{cccccccc}
\hline Contract & Ital. & Non-Ital. & Total Cases & Job Grade & Ital. & Non-Ital. & Total Cases \\
\hline Perm. FT & 20.3 & 1.9 & 10.4 & Basic agric. worker * & 51.7 & 86.1 & 70.1 \\
Fixed-term & 63.3 & 96.2 & 81.0 & Qualified worker ** & 25.0 & 12.0 & 18.0 \\
Other & 16.4 & 1.9 & 8.6 & Specialized work*** & 14.3 & 1.5 & 7.5 \\
Total & 100.0 & 100.0 & 100.0 & Non-manual & 7.3 & 0.0 & 3.4 \\
Base & 232 & 267 & 499 & Other & 1.7 & 0.4 & 1.0 \\
& & & & Total & 100.0 & 100.0 & 100.0 \\
& & & & Base & 232 & 267 & 499 \\
\hline
\end{tabular}

Specific Italian job grades: ${ }^{*}=$ operaio comune, ${ }^{* *}=$ operaio qualificato, ${ }^{* * *}=$ operaio specializzato.

Table 7. Years worked for current employer, broken down by employer's sector (\% values).

\begin{tabular}{cccccc}
\hline Years Worked for & \multicolumn{4}{c}{ Sector } & \multirow{2}{*}{ Total Cases } \\
\cline { 2 - 5 } Current Employer & Viti-Culture & Fruit and Vegetables & Livestock & Other & \\
\hline Up to 1 year & 24.1 & 25.2 & 8.0 & 16.9 & 20.4 \\
From 1 to 5 years & 51.9 & 38.8 & 28.4 & 43.7 & 40.8 \\
From 6 to 10 years & 15.7 & 22.0 & 37.5 & 16.9 & 22.4 \\
Over 10 years & 8.3 & 14.0 & 26.1 & 22.5 & 16.4 \\
Total & 100.0 & 100.0 & 100.0 & 100.0 & 100.0 \\
Base & 108 & 214 & 88 & 89 & 499 \\
\hline
\end{tabular}

Table 8. Reasons leading to choice of position with current employer, broken down by job grade and (Italian/non-Italian) origin (\% values).

\begin{tabular}{ccccccccc}
\hline \multirow{2}{*}{ Reasons for Choice } & \multicolumn{4}{c}{ Job Grade } & \multicolumn{3}{c}{ Origin } & \multirow{2}{*}{ Per Cent of Cases } \\
\cline { 2 - 7 } & Basic & Qual. & Spec. & Non-man. & Ot. & Ital. & Non-Ital. & \\
\hline First job I found & 26.6 & 25.6 & 27.0 & 11.8 & 0.0 & 23.7 & 27.3 & 25.7 \\
It was the job I wanted & 18.6 & 37.8 & 37.8 & 47.1 & 40.0 & 35.3 & 15.4 & 24.6 \\
The need to earn money & 56.9 & 27.8 & 18.9 & 17.6 & 0.0 & 25.4 & 65.5 & 46.9 \\
Good working conditions & 17.4 & 28.9 & 32.4 & 41.2 & 0.0 & 26.3 & 16.9 & 21.1 \\
Close to home & 20.9 & 26.7 & 27.0 & 5.9 & 40.0 & 30.2 & 15.0 & 22.0 \\
No alternative option & 13.4 & 7.8 & 13.5 & 0.0 & 20.0 & 9.9 & 13.9 & 12.0 \\
Other & 3.4 & 7.8 & 5.4 & 17.6 & 40.0 & 9.9 & 1.1 & 5.2 \\
Base & 350 & 90 & 37 & 17 & 5 & 232 & 267 & 499 \\
\hline
\end{tabular}

Our multidimensional analysis of work culture examines the value attributed to work, and thus the position assigned to work in the ranking of important areas of life. As Table 11 indicates, the top positions are occupied by three areas that connote a set of values: family, work and financial resources. The standard deviation associated with each of the mean values in the table gives an indication of the consistency of the respondents' evaluations. If, again, we imagine the table divided into three bands, we find that "freedom and democracy" joins "family", "work" and "financial resources" in the upper section. To some extent, therefore, the upper portion of the rankings can be seen to be based on values associated with work and family, but with an undercurrent of concern for freedom and the health of democratic institutions. The lower section of the list is populated by different forms of engagement: in society, in religion and in politics. However, the last two (religion and political engagement) display a greater standard deviation than the other factors, indicating a greater divergence in the group in relation to the mean value (and therefore revealing a greater variety of positions). 
Table 9. Ranking of job characteristics by importance attributed (mean values and standard deviation).

\begin{tabular}{cccc}
\hline Job Characteristics & Mean & Std. dev. & Base \\
\hline Having a stable job (permanent position, etc.) & 4.13 & 0.84 & 498 \\
Relationships with colleagues & 3.99 & 0.83 & 496 \\
Showing what I can do (using my skills, etc.) & 3.97 & 0.86 & 494 \\
Being appreciated for my work & 3.96 & 0.87 & 492 \\
Pay (wages, bonuses, etc.) & 3.86 & 0.84 & 498 \\
Work environment (safety, noise, hazards, etc.) & 3.78 & 0.99 & 494 \\
Balance between work and other areas of life & 3.76 & 0.97 & 489 \\
Opportunity for variety of work activities & 3.52 & 1.00 & 495 \\
Working autonomously, without much supervision & 3.39 & 1.09 & 496 \\
Work load and work rhythms (intensity, etc.) & 3.30 & 0.83 & 491 \\
Involvement in enterprise's decision-making proc. & 2.87 & 1.23 & 492 \\
\hline
\end{tabular}

Table 10. Ranking of job characteristics by value attributed: comparison between Italian and non-Italian respondents (mean values).

\begin{tabular}{cccc}
\hline Italians & & Non-Italians & Mean \\
\hline Job Characteristics & Mean & Job Characteristics & 4.10 \\
Having a stable job & 4.16 & Having a stable job & 3.94 \\
Relationships with colleagues & 4.06 & Relationships with colleagues & 3.92 \\
Being appreciated for my work & 4.05 & Showing what I can do & 3.87 \\
Work environment & 4.03 & Being appreciated for my work & 3.82 \\
Showing what I can do & 4.03 & Pay & 3.63 \\
Pay & 3.92 & Balance of work and other areas & 3.56 \\
Balance of work and other areas & 3.92 & Work environment & 3.46 \\
Opportunity for variety of activities & 3.59 & Opportunity for variety of activities & 3.35 \\
Working autonomously & 3.44 & Working autonomously & 3.24 \\
Work load and work rhythms & 3.36 & Work load and work rhythms & 2.73 \\
\hline Involvement in decision-making pr. & 3.04 & Involvement in decision-making pr. \\
\hline
\end{tabular}

Base: Italians from 230 to 232; Non-Italians from 257 to 266.

Table 11. Ranking of different areas of life, by importance attributed (mean values and standard variation).

\begin{tabular}{cccc}
\hline Areas of Life & Mean & Std. dv. & Base \\
\hline Family & 4.60 & 0.63 & 499 \\
Work & 4.32 & 0.70 & 499 \\
Financial resources & 4.14 & 0.82 & 498 \\
Freedom and democracy & 4.05 & 0.97 & 495 \\
Social equality & 3.97 & 0.98 & 495 \\
Opportunities for cultural enrichment & 3.87 & 0.97 & 499 \\
Free time & 3.78 & 0.94 & 499 \\
Friends & 3.77 & 0.96 & 499 \\
Solidarity /nclusiveness & 3.68 & 0.95 & 496 \\
Social engagement & 3.50 & 0.91 & 496 \\
Religion & 3.18 & 1.30 & 496 \\
Political engagement & 2.05 & 1.06 & 495 \\
\hline
\end{tabular}

Having considered the aspects of work the respondents deem most important, as well as their wider value system, our exploration of the participants' work culture brought us to the question of how they viewed certain changes in the world of work. A question was included in the questionnaire that invited the participants to evaluate whether certain behaviours on the part of an employer/enterprise, or on the part of a worker or workers, could be considered justified. As Table 12 makes clear, the respondents generally agreed with the principle of increasing or decreasing workforce size of in line with a business's requirements, and with the idea of linking pay to business performance. They were 
largely in favour of pay being linked to individual performance and bonuses for working overtime. On the other hand, they were contrary to the idea of having to change jobs frequently over the course of a career, and largely against the idea of being compelled to accept either low wages to secure work, or having to accept being exposed to health risks. In general, we find the group views the need for flexibility -in terms of workforce size, working hours and pay-in positive terms, whereas having to change jobs, being compelled to accept low wages, and being exposed to health risks were viewed negatively.

Table 12. Respondents' opinions about certain changes seen currently in the world of work (\% values).

\begin{tabular}{cccccc}
\hline It Is Right That ... & Agree & Don't Agree & Don't Know & Total & Base \\
\hline The workforce is increased or decreased to fit the business's needs & 52.1 & 22.8 & 25.1 & 100.0 & 495 \\
Pay is linked to the performance of the business & 50.9 & 32.7 & 16.4 & 100.0 & 495 \\
Pay is linked to individual performance & 62.4 & 22.2 & 15.4 & 100.0 & 495 \\
Workers have to accept lower pay in order to work & 21.2 & 68.1 & 10.7 & 100.0 & 495 \\
Employees work beyond the hours agreed & 64.8 & 25.3 & 9.9 & 100.0 & 495 \\
Workers have to change jobs frequently over their careers & 30.5 & 56.4 & 13.1 & 100.0 & 495 \\
Workers may have to accept some risk to their health at work & 10.7 & 81.6 & 7.7 & 100.0 & 495 \\
\hline
\end{tabular}

With a view to further investigating the different aspects of quality of working life, the participants were given a list of elements to evaluate, these being subdivided according to the dimensions of job quality we described earlier (complexity, autonomy, control and the economic, ergonomic and symbolic dimensions of work). Specifically, the participants were asked to what extent, under normal circumstances, was each dimension a feature of their job, to which they could respond "never", "rarely", "quite often", "frequently" or "always". This scale was subsequently translated into a score from 1 ("never") to 5 ("always"), and a mean value calculated for each element of analysis. As far as the quality of the work-life relationship was concerned, we were interested in the question of balance between work and other areas of life. We therefore asked to what extent certain aspects of work had an impact on other areas of life, and vice versa ("not at all", "not much", "a little", "quite a lot", and "a great amount"). In this case, too, in order to calculate a mean score for each aspect, the answers were translated into a scale of 1 to 5 . It should be noted, however, that for two of the dimensions (the ergonomic dimension and that of work-life balance), the effect of the mean values indicated on quality of working life is inverse in relation to those for the other aspects. In other words, when we measure the prevalence, in the former case, of factors that are deemed deleterious to the ergonomic dimension of a job (extremes of temperature, lifting heavy loads, etc.), and the extent to which, in the latter case, aspects of work have an impact on other areas of life (and vice-versa), the greater the value assigned to these factors, the greater the ergonomic burden of the job and/or its impact on other areas of life and - as such — the lower the quality of working life.

In Table 13, we see that, generally speaking, the highest mean values are those for the symbolic dimension, and that the figures for the ergonomic dimension are also relatively high. In the work-life balance section of the table, the impact of work on other areas of life is scored higher than the impact in the opposite direction. As far as the economic dimension is concerned, even though the score for pay is relatively high, the other factors bring down the overall value. In terms of complexity, the factors that carry greatest weight are the "opportunity to learn new things", and the variety of the tasks carried out. Even if the scores might appear a little on the low side in general (remember, the scale was from 1 to 5), they are particularly low for the factors pertaining to the dimensions of autonomy and control.

For each of the seven dimensions of quality of working life we have analysed by generating these mean values, we determined a composite dimension indicator. Here, too, we used a scoring system from 1 to 5 , proceeding as follows: first of all, the scores for the four constituent aspects of each dimension of job quality were added, producing a total score between 4 (all answers "never") and 20 (all answers "always"). This scale from 4 to 20 was then subdivided into four bands: a score of 4-7 was classed as "low", 8-11 as "medium-low", 12-15 as "medium-high" and 16-20 as "high". At this point, using each participant's scores, it was possible to recalculate, for each dimension, the 
distribution of the sample group across the four levels of the composite indicator (Table 14). For the dimension of work-life balance (which included only two constituent aspects), an analogous process was followed. In this case, however, the dimension total varied from 2 to (both answers "not at all") to 10 (both answers "a great amount"). This scale was also divided into four levels: 2-3 classed as "low", 4-5 as "medium-low", 6-7 as "medium-high", and 8-10 as "high". When calculating the composite indicator for two of the dimensions - the ergonomic dimension and that of work-life balance-we inverted the scale of values. Indeed as mentioned previously, in contrast to the other dimensions these measured the prevalence of burdensome ergonomic conditions (in the former case), and the extent to which work and other areas of life impacted upon one another (in the latter). To facilitate our analysis and the process of forming comparisons between the different dimensions, it was therefore necessary to invert the four levels of the indicator for these two dimensions so that they read in a consistent manner, i.e., with "low" connoting poor quality of working life, and "high" connoting good quality of working life.

Table 13. Aspects of the quality of working life (mean values and standard deviation).

\begin{tabular}{|c|c|c|c|}
\hline Elements of Work Subject to Evaluation & Mean & Std. dev. & Base \\
\hline \multicolumn{4}{|l|}{ - Economic dimension } \\
\hline Adequate monthly pay (wages) & 3.62 & 1.11 & 495 \\
\hline Bonuses linked to objectives, workloads, etc. & 1.55 & 1.07 & 493 \\
\hline Indirect economic benefits (accommodation, meals, etc.) & 2.03 & 1.63 & 495 \\
\hline Other economic benefits (extra payments, etc.) & 1.19 & 0.60 & 496 \\
\hline \multicolumn{4}{|l|}{ - Ergonomic dimension } \\
\hline Extremes of temperature, hazardous substances, etc. & 2.43 & 1.21 & 497 \\
\hline Heavy loads, noise, vibrations, etc. & 2.01 & 1.12 & 497 \\
\hline Time pressures (intensity, work rhythms, etc.) & 2.37 & 1.15 & 497 \\
\hline Risk of physical accidents & 1.76 & 1.02 & 497 \\
\hline \multicolumn{4}{|l|}{ - Complexity } \\
\hline Variety of tasks & 2.66 & 1.21 & 497 \\
\hline Opportunity to learn new things & 2.88 & 1.23 & 496 \\
\hline Unexpected situations and problems to resolve & 2.15 & 1.23 & 495 \\
\hline Tasks that require experience & 2.55 & 1.26 & 492 \\
\hline \multicolumn{4}{|l|}{ - Autonomy } \\
\hline Deciding for oneself when to take breaks & 2.25 & 1.39 & 494 \\
\hline Deciding for oneself how to carry out tasks & 1.83 & 1.18 & 493 \\
\hline Deciding one's own workload & 1.54 & 0.98 & 492 \\
\hline Deciding for oneself what type of task to do & 1.46 & 0.98 & 491 \\
\hline \multicolumn{4}{|l|}{ - Control } \\
\hline Employer's willingness to discuss work-related problems & 3.27 & 1.28 & 492 \\
\hline Meetings with employer to plan work activities & 1.73 & 1.20 & 491 \\
\hline Meetings for planning working methods and work organ. & 1.61 & 1.07 & 488 \\
\hline Meetings to decide what to do, or what to produce & 1.52 & 1.05 & 489 \\
\hline \multicolumn{4}{|l|}{ - Symbolic dimension } \\
\hline Being trusted by the business owner & 3.77 & 1.04 & 480 \\
\hline Receiving help from colleagues & 3.74 & 1.04 & 494 \\
\hline Recognition from family & 3.90 & 1.07 & 487 \\
\hline Recognition from society & 3.31 & 1.11 & 478 \\
\hline \multicolumn{4}{|l|}{ - Work-life balance } \\
\hline $\begin{array}{l}\text { Work has an impact on other areas of life (looking after family, } \\
\text { housework, relationships with friends, etc.) }\end{array}$ & 3.13 & 0.99 & 488 \\
\hline $\begin{array}{l}\text { Other areas of life have an impact on work (time available for } \\
\text { work, professional development, education and training, etc.) }\end{array}$ & 2.33 & 0.99 & 488 \\
\hline
\end{tabular}


Table 14. Level of quality of working life (QoWL), by dimension (\% values).

\begin{tabular}{cccccccc}
\hline \multirow{2}{*}{ Level of QoWL } & \multicolumn{7}{c}{ Dimension Of Quality Of Working Life } \\
\cline { 2 - 7 } & Economic & Ergonomic & Complexity & Autonomy & Control & Symbolic & Work-Life \\
\hline Low & 42.7 & 4.0 & 23.7 & 61.6 & 49.1 & 1.8 & 8.8 \\
Med-low & 43.1 & 17.5 & 41.8 & 27.1 & 34.5 & 11.7 & 44.9 \\
Med-high & 11.8 & 34.4 & 25.2 & 8.1 & 10.5 & 47.7 & 36.5 \\
High & 2.4 & 44.1 & 9.3 & 3.2 & 5.9 & 38.8 & 9.8 \\
Total & 100.0 & 100.0 & 100.0 & 100.0 & 100.0 & 100.0 & 100.0 \\
Base & 497 & 497 & 497 & 494 & 493 & 495 & 488 \\
\hline
\end{tabular}

Table 14, then, shows the distribution, for each dimension, of the sample respondents across the various levels of the composite indicator of quality of working life. As we examine the table, three fairly distinct areas emerge. Firstly, as a whole, the sample respondents claim to experience good quality of working life in relation to ergonomic conditions and symbolic recognition of their work. It is likely that the work environments in which they are employed are of a good standard, that a lot is asked of them, and that they find the social environment predominantly positive. At the intermediate level, we find the dimensions of work-life balance and complexity. The sample group reports a good level of balance between different areas of life (work and otherwise), and one participant in three claims not to feel his or her job is highly repetitive. In both dimensions, however, more than half of the respondents are grouped in the lowest two bands of the composite indicator. Even more problematic are the dimensions in the third group, the economic dimension and those of control and autonomy. This suggests that the sample group is engaged in work that does not tend to have much scope for personal initiative, operational or organizational self-determination, or participation in the business's decision-making processes. It is above all in the dimension of autonomy that we see the sample group occupy a low overall position.

The quality of working life dimensions, as we said, have their own specificity, conceptual and analytical, and the model presented does not provide for the construction of a synthetic indicator (which aggregates very different measuring elements), but considers instead important to study the relationship between dimensions. In this case, the statistical analysis revealed four intensity levels of the relationship between dimensions: (1) a strong direct relationship between dimensions of complexity and autonomy; (2) a good direct relationship between dimensions of complexity and control, between dimensions of autonomy and control, and a good inversed relationship between ergonomic dimension and dimension of complexity; (3) a discrete direct relationship between dimensions of control and symbolic dimension and between economic and symbolic dimensions; (4) a low but noteworthy direct relationship between economic dimension and dimension of control, between ergonomic and symbolic dimensions, between ergonomic and work-life balance dimensions; and a low but noteworthy inversed relationship between dimensions of complexity and work-life balance, between economic and work-life balance dimensions, between dimensions of control and work-life balance. The analysis of relationship between dimensions helps us to understand how in the examined context there are different levels of relationship between the working condition elements, and how some relationships are relevant, and therefore important to be considered in delineating an interpretative framework.

We also examined the question of quality of working life in terms of other areas (work hours, training, perceptions regarding risks, etc.), which we are unable to expand upon here. We will, however, mention a piece of subjective data: $46.4 \%$ of the respondents declared themselves very satisfied with their job, $43.8 \%$ claimed to be reasonably satisfied, $7.8 \%$ not very satisfied, and $2.0 \%$ not satisfied at all. Table 15 indicates the level of satisfaction in relation to seven aspects, which the participants were asked to evaluate. These aspects correspond with the seven dimensions of quality of working life analysed above. If we compare the data for the respondents' level of satisfaction (Table 15) with that in the multidimensional grid used to analyse quality of working life (Table 12), we note that there is greatest agreement in the high scores attributed to aspects relating to the work environment, appreciation 
for work done and the compatibility between work and other areas of life. The participants' lack of satisfaction with issues of participation is also confirmed. The two data sets are less consistent, however, in relation to the other three dimensions. For the dimension of autonomy, and to a lesser extent for those of task complexity and pay, subjectively the participants claim to be satisfied, even though this does not translate into high scores in the objective evaluation of their working conditions.

Table 15. Satisfaction level with different aspects of participant's job (\% values).

\begin{tabular}{ccccccc}
\hline \multirow{2}{*}{ Aspect of Job } & \multicolumn{7}{c}{ Level of Satisfaction } & \multirow{2}{*}{ Total } \\
\cline { 2 - 6 } & Not at All & Not Very & Rea Son Ably & Very & Extremely & \\
\hline Pay & 0.8 & 7.6 & 52.8 & 31.5 & 7.3 & 100.0 \\
Work environment & 2.2 & 10.6 & 46.7 & 30.7 & 9.8 & 100.0 \\
Nature of tasks performed & 2.4 & 7.3 & 46.9 & 34.7 & 8.7 & 100.0 \\
Level of autonomy & 1.6 & 8.2 & 44.7 & 36.0 & 9.5 & 100.0 \\
Involvem. in decision-making & 12.7 & 23.9 & 37.9 & 19.1 & 6.4 & 100.0 \\
Appreciation for work done & 3.7 & 8.1 & 41.2 & 36.2 & 10.8 & 100.0 \\
Work-life balance & 3.6 & 13.2 & 40.9 & 31.0 & 11.3 & 100.0 \\
\hline
\end{tabular}

Base values: Pay $=489$, Work environment $=492$, Nature of tasks performed $=493$, Level of autonomy $=486$, Involvement in decision-making $=472$, Appreciation for work done $=481$, Work-life balance $=477$.

\subsection{Discussion}

Over the preceding pages, we have presented a model framework for analysing quality of working life which we believe will prove useful for effectively translating the concept of sustainability in relation to workers and their working conditions. This model effects an integrated interpretation of the various dimensions of work culture and quality of working life.

The world of agricultural work is changing, with the rate of innovation gathering pace in terms of the products produced, the processes used to do so (technologies, required skills, etc.) and the way work and businesses are organized, not to mention the changing relationship between producers and consumers. Changes that we also will have to consider over the coming years in relation to the sustainability of the conditions affecting what is, in social terms, a very varied population of agricultural workers. The theoretical and methodological approach we have formulated here is one that harnesses the multidimensional nature of the quality of working life to bring certain objective characteristics and subjective evaluations into clearer focus, and thus provide a means for examining work sustainability. The model presented has been accompanied by a number of illustrative results produced in the course of a research project that involved a sample group of employees from farms and agricultural businesses. Based on these results, we have identified three levels of quality of working life: a "good" level, in respect to ergonomic conditions and symbolic recognition/appreciation; an "adequate" level, in terms of work-life balance and job complexity; and a "problematic" level, in respect to economic reward and questions of control and autonomy. Despite the fact that, subjectively, the sample group reports a relatively high level of satisfaction, we can therefore suggest that there is room for improvement, particularly in relation to the aspects of organizational and operational self-determination, economic conditions, the nature and variety of tasks, and involvement in decision-making processes.

Although the primary scope of these notes is to present an analytical model, the data gathered in the field—as part of the study discussed—suggest that to achieve a level of sustainability, agricultural work must offer improved opportunities for greater stability (financial and otherwise), as well as greater involvement in decision-making processes and everyday organizational and operational choices. However, as we have maintained during the presentation of our analytical model, we should also consider the "work culture" of the workers in the sector. In the case presented, we see that they invest the greatest significance in relational aspects and stability. In the minds of the participants, therefore, the qualities that define a good job are security and a good social environment, followed by opportunities for growth and symbolic recognition. Opportunities for involvement in decision-making processes and autonomy, meanwhile, appear to be of less importance to them. One avenue for further 
exploration of the sustainability of working conditions in the agricultural sector is therefore to analyse how these attitudes came to be formed, in relation both to objective conditions, and to subjective evaluations of satisfaction. Further studies aimed at better understanding the relationship between the importance assigned to certain aspects of a job, subjective evaluations of satisfaction and more objective assessments of quality of working life would also be worthwhile. For instance, how can we interpret the workers' stance in relation to their level of operational autonomy (which is among the aspects of least importance to the workers, and has uninspiring objective ratings but high levels of subjective satisfaction)? The participants' attitudes appear to be more consistent in relation to involvement in decision-making (with similarly low ratings for importance, objective conditions and satisfaction levels) and job complexity (medium-low scores in terms of importance and objective conditions, slightly higher in terms of subjective satisfaction). Whereas, for the ergonomic and symbolic dimensions of their jobs and that of work-life balance, we see a degree of consistency between objective assessment and subjective satisfaction levels (with all three areas rated relatively positively, and ranked mid-table in terms of importance), the issue of economic reward again raises questions, there being a discrepancy between conditions (relatively low), satisfaction (overall quite good) and the significance attached to it (mid-table results).

What appears to us to be the key message, however, is the need to analyse and understand sustainability of working conditions (both in agriculture and other sectors) in respect to multiple, independent dimensions, in both objective and subjective terms, and in relation to the scale of importance attributed by the worker to each aspect of the job and the significance of work in his or her wider value system.

\section{Conclusions}

In conclusion, we are left with a fundamental question: why is quality of work important for social sustainability? We believe that the answer is to be found in the central importance that work continues to have for so many people. For all that we are living through an age characterized by (recent [65] and not-so-recent [66]) forecasts of the end of work as we know it, it is clear that for many people work remains the principal source of income. Many would also maintain that work can be a source of growth, of emancipation, and identity - a source of sense, essentially. For this reason, we continue to register a yearning for "meaningful" work that engages and makes demands of the worker on a cognitive level, that can be a source of meaningful experience. The question of "social sustainability", therefore, cannot be separated from that of "job sustainability".

In this regard, the proposed multidimensional framework for analysing quality of working life allows us both to study the question of "job sustainability" and at the same time to consider a number of key issues relating to the wider debate on "social sustainability" at a time of great upheaval in today's capitalist systems. Focusing specifically on issues associated with work, and, in particular, on the problematic social consequences of some of the changes we are witnessing, we can identify, at least in broad terms, a number of key lines of argument.

The first concerns uncertainty and social insecurity, and is well represented, for instance, in the works of Bauman $[67,68]$ and Castel $[69,70]$, who both demonstrate how changes in the world of work lead to an increase in social vulnerability. We may also consider the prevalence of discontinuity in workers' careers, and more generally, processes that have led to widespread insecurity and the entrenchment of a risk society [71].

Our framework for assessing quality of working life can also help us to delve deeper into the processes by which this insecurity propagates, and thereby to identify different sets of circumstances. Indeed, a condition of risk that tends towards the global, and the general, is accompanied by the continuation and entrenchment of social inequality. This is the second line of discussion that we wish to reference. Using the very multidimensional analytical framework we have presented here, we are able to trace how work-related issues lie at the heart of inequality [72], and make sense of the processes 
that are contributing to the "hourglass" shape of job markets, where we see an increasing polarization of qualifications and economic conditions.

Uncertainty, insecurity and inequality translate into precariousness, another major issue that has been highlighted for some time in the field of sociology [73], with attention devoted specifically to processes that have led to greater demands for flexibility in working life [74,75]. Precariousness is a complex social condition. To really make sense of it, we need to examine the relationship between the specifics of the person (educational background, family resources, type of contract, etc.) and the wider context in which he or she lives (job market, etc.). By approaching the question from the perspective of quality of working life, we can begin to unravel the heterogeneous character of precariousness and view it, in "processual terms", as a condition in a state of realization, one that is affecting a large section of the population [20].

If to exist in a state of uncertainty and precariousness makes it impossible to identify oneself with one's work on an on-going basis [20], we should also consider a fourth and final area of discussion, which relates to the question of recognition. In an age of increasing organizational complexity, fragmentation and discontinuity in the world of work, recognition becomes an issue of importance at both the individual and societal level. It is for this reason that we have introduced a symbolic dimension-which is expressly concerned with measuring work-related well-being in relation to various aspects, including that of recognition-to our analytical model. A central theme in sociological literature [76], recognition should be considered with particular regard to the changes we have witnessed in the world of work, changes that have heightened levels of personal isolation [77]. Along with respect, it has become an object of negotiation in our day-to-day relationships [78]. Questions of recognition, respect and trust have all been made more problematic by certain changes in the field of work. They should therefore be considered both as essential, symbolic, identity-related resources [79], and as factors with the potential to determine an individual's quality of working life.

What we have outlined above are just some of the major issues with which the field of sociology has grappled in recent years, particularly in view of the changes we have witnessed in the world of work. These areas of study can help us to understand in what way social phenomena are the product of a multiplicity of interacting causes. "Sustainability of work" is inevitably a prerequisite for "social sustainability", not only inasmuch as work is necessary if people are to sustain themselves, but also because it is a means to experiencing meaning.

Acknowledgments: This research has been financed by AGRI.BI, the bilateral organization representing the companies and workers working in the agricultural sector of the province of Verona. Giorgio Gosetti was the scientific director of research, which was supported by a team of researchers who found the information in the field. The final and complete research report was published by an Italian publisher. For the work done and for the collaboration provided in various stages of the research, the author is grateful to the research team, the companies involved and the participating workers. All subjects gave their informed consent for inclusion before they participated in the study. The study was conducted in accordance with the Declaration of Helsinki.

Author Contributions: Giorgio Gosetti designed the study, analysed the data and wrote the paper.

Conflicts of Interest: The author declares no conflict of interest.

\section{References}

1. Meadows, D.; Meadows, D.; Randers, J. Limits to Growth: The 30-Year Update; Chelsea Green Publishing Company: White River Junction, VT, USA, 2004.

2. Magatti, M.; Gherardi, L. Una Nuova Prosperità. Quattro vie Per Una Crescita Integrale; Feltrinelli: Milan, Italy, 2012.

3. Latouche, S. Limite; Bollati Boringhieri: Turin, Italy, 2012.

4. Rullani, E. Produzione sostenibile: La nuova stella polare per navigare (a vista) dentro il mare della crisi. Econ. Soc. Reg. 2011, 114, 5-21.

5. Bertell, L.; de Cordova, F.; De Vita, A.; Gosetti, G. Senso del Lavoro Nelle Economie Diverse: Uno Studio Interdisciplinare; FrancoAngeli: Milan, Italy, 2017.

6. Velten, S.; Leventon, J.; Jager, N.; Newig, J. What Is Sustainable Agriculture? A Systematic Review. Sustainability 2015, 7, 7833-7865. [CrossRef] 
7. DeLonge, M.S.; Miles, A.; Carlisle, L. Investing in the transition to sustainable agriculture. Environ. Sci. Policy 2016, 55, 266-273. [CrossRef]

8. Veisi, H.; Liaghati, H.; Alipour, A. Developing an ethics-based approach to indicators of sustainable agriculture using analytic hierarchy process (AHP). Ecol. Indicat. 2016, 60, 644-654. [CrossRef]

9. Food and Agriculture Organization of the United Nations (FAO). SAFA-Sustainability Assessment of Food and Agriculture Systems, Guidelines; FAO: Rome, Italy, 2014.

10. ILO (International Labour Organization). Decent Work: Report of the Director-General, International Labour Conference; ILO: Geneva, Switzerland, 1999.

11. ILO (International Labour Organization). Decent work; ILO: Geneva, Switzerland, 2004.

12. Boyer, R.; Freyssenet, M. Les Modeles Productifs; La Découverte: Paris, France, 2000.

13. Borghi, V. La presa della rete: Tendenze e paradossi del nuovo spirito del capitalismo. Rassegna Ital. Sociol. 2011, 3, 445-460. [CrossRef]

14. Butera, F.; Alberti, F. Il governo delle reti inter-organizzative per la competitività. Stud. Organ. 2012, 1, 77-111. [CrossRef]

15. Cattero, B. Le trasformazioni dell'impresa e i contesti istituzionali. In La Sociologia Economica Contemporanea; Regini, M., Ed.; Laterza: Roma-Bari, Italy, 2007.

16. Gallino, L. Finanzcapitalismo: La Civiltà del Denaro in Crisi; Einaudi: Torino, Italy, 2011.

17. Gosetti, G. Organizzazione, lavoro, persone: Vecchio e nuovo nella rete organizzativa. In Lavoro e Lavori. Strumenti Per Comprendere il Cambiamento; Gosetti, G., Ed.; FrancoAngeli: Milano, Italy, 2011.

18. Rullani, E. Economia Della Conoscenza: Creatività e Valore Nel Capitalismo Delle Reti; Carocci: Roma, Italy, 2004.

19. Murgia, A. Dalla Precarietà Lavorativa Alla Precarietà Sociale: Biografie in Transito Tra Lavoro e Non Lavoro; Odoya: Bologna, Italy, 2010.

20. Standing, G. The Precariat: The New Dangerous Class; Bloomsbury Academic: London, UK; New York, NY, USA, 2011.

21. Gallino, L. Globalizzazione della precarietà. In Precarietà del Lavoro e Società Precaria Nell'Europa Contemporanea; Masulli, I., Ed.; Carocci: Roma, Italy, 2004.

22. Fullin, G. Vivere L'instabilità del Lavoro; Il Mulino: Bologna, Italy, 2004.

23. Chicchi, F.; Leonardi, E. Lavoro in Frantumi: Condizione Precaria, Nuovi Conflitti e Regime Neoliberista; Ombre Corte: Verona, Italy, 2011.

24. Contarini, S.; Marsi, L. Precariato: Forme e Critica Della Condizione Precaria; Ombre Corte: Verona, Italy, 2015.

25. Borghi, V.; Zamponi, M. Terra e lavoro nel capitalismo contemporaneo. Sociol. Lav. 2012, 128, 176.

26. Pugliese, E. I Braccianti Agricoli in Italia; FrancoAngeli: Milan, Italy, 1981.

27. Borghi, V. Di cosa ci parlano i contadini, oggi? Sociol. Lav. 2012, 128, 7-15. [CrossRef]

28. Perrotta, D.; Sacchetto, D. Il ghetto e lo sciopero: Braccianti stranieri nell'Italia meridionale. Sociol. Lav. 2012, 128, 152-166. [CrossRef]

29. Van der Ploeg, J.D. Terra e lavoro: Due questioni apparentemente dimenticate, di nuovo nell'agenda europea. Sociol. Lav. 2012, 128, 46-60. [CrossRef]

30. Sage, C. Enviroment and Food; Routledge: Abingdon, UK, 2012.

31. Dunford, R. Peasant activism and the rise of food sovereignty: Decolonising and Democratising norm diffusion? Eur. J. Int. Relat. 2017, 23, 145-167. [CrossRef]

32. Landert, J.; Schader, C.; Moschitz, H.; Stolze, M. A Holistic Sustainability Assessment Method for Urban Food System Governance. Sustainability 2017, 9, 490. [CrossRef]

33. Pretty, J.; Sutherland, W.J.; Ashby, J.; Auburn, J.; Baulcombe, D.; Bell, M.; Bentley, J.; Bickersteth, S.; Brown, K.; Burke, J.; et al. The top 100 questions of importance to the future of global agriculture. Int. J. Agric. Sustain. 2010, 8, 219-236. [CrossRef]

34. Sage, C. Addressing the Faustian bargain of the modern food system: Connecting sustainable agriculture with sustainable consumption. Int. J. Agric. Sustain. 2012, 10, 204-207. [CrossRef]

35. Martin, S.A.; Clapp, J. Finance for Agriculture or Agriculture for Finance? J. Agrar. Chang. 2015, 15, 549-559. [CrossRef]

36. Dalgaard, T.; Hutchings, N.J.; Porter, J.R. Agroecology, scaling and interdisciplinarity. Agric. Ecosyst. Environ. 2003, 100, 29-51. [CrossRef]

37. Bertell, L.; Deriu, M.; De Vita, A.; Gosetti, G. Davide e Golia: La Primavera delle Economie Diverse; Jaka Book: Milan, Italy, 2013. 
38. Gosetti, G. Lavorare Nell'impresa Artigiana. Cultura del Lavoro e Qualità Della Vita Lavorativa; FrancoAngeli: Milan, Italy, 2014.

39. Gosetti, G. Qualità Della Vita Lavorativa Nelle Organizzazioni Complesse: Il Caso Dei Servizi di Salute Mentale; FrancoAngeli: Milan, Italy, 2016.

40. Gosetti, G. Lavoratori Dell'agricoltura: Percorsi, Culture, Condizioni; FrancoAngeli: Milan, Italy, 2017.

41. Ahmad, S. Paradigms of Quality of Work Life. J. Hum. Values 2013, 19, 73-82. [CrossRef]

42. Serey, T.T. Choosing a robust quality of work life. Bus. Forum 2006, 27, 7-10.

43. Eurofound-European Foundation for the Improvement of Living and Working Conditions. Fifth European Working Conditions Survey. In Overview Report; Eurofound: Dublin, Germany, 2012.

44. Eurofound-European Foundation for the Improvement of Living and Working Conditions. Trends in job quality in Europe. In A Report Based on the Fifth European Working Conditions Survey; Eurofound: Dublin, Germany, 2012.

45. Gallie, D. Production Regimes, Employment Regimes, and the Quality of Work. In Employment Regimes and the Quality of Work; Gallie, D., Ed.; Oxford University Press: Oxford, UK, 2007.

46. Gallie, D. Production Regimes and the Quality of Employment in Europe. Annu. Rev. Sociol. 2007, 33, 85-104. [CrossRef]

47. Rose, M. Good Deal, Bad Deal? Job Satisfaction in Occupations. Work Employ. Soc. 2003, 17, 504-530. [CrossRef]

48. Green, F. Why has work effort become more intense? Ind. Relat. 2004, 43, 709-741. [CrossRef]

49. Green, F. Subjective employment insecurity around the world. Camb. J. Reg. Econ. Soc. 2009, 2, $343-363$. [CrossRef]

50. Muñoz de Bustillo, R.; Fernández-Marcías, E.; Esteve, F.; Antón, J.-I. E pluribus unum? A critical survey of job quality indicators. Soc. Econ. Rev. 2011, 9, 447-475. [CrossRef]

51. Gallino, L. Informativa e Qualità Del Lavoro; Einaudi: Turin, Italy, 1983.

52. La Rosa, M. Qualità della vita e qualità del lavoro. Sociol. Lav. 1983, 17-18, 452.

53. Appadurai, A. The Future as Cultural Fact Essays on the Global Condition; Verso: London, UK, 2013.

54. Sen, A. Capability and well-being. In The Quality of Life; Nussbaum, M., Sen, A., Eds.; Clarendon Press: Oxford, UK, 1993; pp. 30-53.

55. Sen, A. Development as Freedom; Oxford University Press: Oxford, UK, 1999.

56. Nussbaum, M. Creating Capabilities: The Human Development Approach; The Belknap Press of Harvard University Press: Cambridge, UK, 2011.

57. Bourdieu, P. Réponses: Pour une Anthropologie Réflexive; Éditions du Seuil: Paris, France, 1992.

58. Bourdieu, P. Raison Pratiques: Sur la Théorie de L'action; Éditions du Seuil: Paris, France, 1994.

59. Gallie, D.; Gosetti, G.; La Rosa, M. Qualità del lavoro e della vita lavorativa. Cosa è cambiato e cosa sta cambiando. Sociol. Lav. 2012, 127, 272.

60. Gualtieri, V. Le Dimensioni Della Qualità del Lavoro: I Risultati Della III Indagine Isfol Sulla Qualità del Lavoro; ISFOL: Rome, Italy, 2013.

61. Gallie, D.; Felstead, A.; Green, F. Changing Patterns of Task Discretion in Britain. Work Employ. Soc. 2004, 18, 243-266. [CrossRef]

62. Gallie, D. Direct participation and the quality of work. Hum. Relat. 2013, 66, 453-473. [CrossRef]

63. Borzeix, A.; Charles, J.; Zimmermann, B. Réinventer le travail par la participation. Actualité nouvelle d'un vieux débat. Sociol. Trav. 2015, 57, 1-19. [CrossRef]

64. Carrieri, M.; Nerozzi, P.; Treu, T. La Partecipazione Incisiva: Idee e Proposte Per Rilanciare la Democrazia Nelle Imprese; Il Mulino: Bologna, Italy, 2015.

65. Ford, M. Rise of the Robots; Hachette: New York, NY, USA, 2017.

66. Rifkin, J. The End of Work: The Decline of the Global Labor Force and the Dawn of the Post-Market Era; Putnam: New York, NY, USA, 1995.

67. Bauman, Z. The Individualized Society; Polity Press: Cambridge, UK, 2001.

68. Bauman, Z. Collateral Damage: Social Inequalities in a Global Age; Polity Press: Cambridge, UK, 2011.

69. Castel, R. L'Insécurité Sociale: Qu'est-ce Qu'être Protégé? Editions du Seuil: Paris, France, 2003.

70. Castel, R. La Montée des Incertitudes: Travail, Protections, Statut de L'individu; Editions du Seuil: Paris, France, 2009.

71. Beck, U. Risikogesellschaft: Auf Dem Weg in Eine Andere Moderne; Suhrkamp Verlag: Berlin, Germany, 1986. 
72. La Rosa, M.; Morlicchio, E.; Pougam, S. Disuguaglianze oggi: Quanto conta l'occupazione. Sociol. Lav. 2017, $144,214$.

73. Bourdieu, P. La précarité est aujourd'hui partout. In Contre-Feux: Propos Pour Servir à la Résistance Contre l'invasion Néo-Libérale; Liber-Raison: Paris, France, 1998.

74. Sennett, R. The Corrosion of Character: The Personal Consequences of Work in the New Capitalism; Norton \& Company: New York, NY, USA; London, UK, 1998.

75. Gallino, L. Il Costo Umano Della Flessibilità; Laterza: Roma/Bari, Italy, 2005.

76. Honnet, A. Kampf um Anerkennung: Grammatik Sozialer Konflikte; Suhrkamp Verlag: Berlin, Germany, 1992.

77. Sennett, R. Together: The Rituals, Pleasures and Politics of Cooperation; Allen Lane: London, UK, 2012.

78. Sennett, R. Respect in a World of Inequality; Norton \& Company: New York, NY, USA, 2003.

79. Bourdieu, P. Le Sens Pratique; Le Editions de Minuit: Paris, France, 1980.

2017 by the author. Licensee MDPI, Basel, Switzerland. This article is an open access article distributed under the terms and conditions of the Creative Commons Attribution (CC BY) license (http://creativecommons.org/licenses/by/4.0/). 